\title{
Evaluation of the Safety of Three Phenolic Compounds from Dipteryx alata Vogel with Antiophidian Potential
}

\author{
Edson Hideaki Yoshida1, Miriéle Cristina Ferraz¹, Natália Tribuiani' ${ }^{1}$, \\ Renata Vasques da Silva Tavares ${ }^{1}$, José Carlos Cogo ${ }^{2}$, Márcio Galdino dos Santos ${ }^{3}$, \\ Luiz Madaleno Franco", Cháriston André Dal-Belo5, Rone A. De Grandis', \\ Flávia Aparecida Resende6, Eliana Aparecida Varanda6, Pilar Puebla7, \\ Arturo San-Feliciano7, Francisco Carlos Groppo ${ }^{8}$, Yoko Oshima-Franco1 ${ }^{*}$ \\ ${ }^{1}$ Post-Graduate Program in Pharmaceutical Sciences, University of Sorocaba, Sorocaba, Brazil \\ ${ }^{2}$ Serpentarium of the University of Vale do Paraíba, São José dos Campos, Brazil \\ ${ }^{3}$ Post-Graduate Program in Environmental Sciences, Tocantins Federal University, Palmas, Brazil \\ ${ }^{4}$ Methodist University of Piracicaba, Piracicaba, Brazil \\ ${ }^{5}$ Laboratory of Neurobiology and Toxinology, Federal University of Pampa, São Gabriel, Brazil \\ ${ }^{6}$ Department of Biological Sciences, São Paulo State University, Araraquara, Brazil \\ ${ }^{7}$ Department of Pharmaceutical Chemistry, Salamanca University, Salamanca, Spain \\ ${ }^{8}$ Department of Physiological Sciences, University of Campinas, Piracicaba, Brazil \\ Email: *yoko.franco@prof.uniso.br
}

Received 30 December 2014; accepted 3 February 2015; published 6 February 2015

Copyright (C) 2015 by authors and Scientific Research Publishing Inc.

This work is licensed under the Creative Commons Attribution International License (CC BY). http://creativecommons.org/licenses/by/4.0/

(c) (i) Open Access

\section{Abstract}

Phenolic compounds from Dipteryx alata Vogel were assayed against the in vitro neurotoxic effect induced by Bothrops jararacussu (Bjssu) venom. Mutagenicity was assessed by the Ames test using Salmonella typhimurium strains TA98, TA97a, TA100, and TA102, in experiments with and without metabolic activation. Anti-bothropic activity was obtained by using mouse phrenic nerve-diaphragm (PND) preparation and myographic technique. Control experiments with physiological Tyrode solution were used for keeping the PND preparations alive $(n=4)$. Concentrations of phenolic compounds were as follow: protocatechuic and vanillic acids $(200 \mu \mathrm{g} / \mathrm{mL}, \mathrm{n}=4)$, vanillin $(50$ $\mu \mathrm{g} / \mathrm{mL}, \mathrm{n}=4)$. These compounds were used alone or pre-incubated with the venom $(40 \mu \mathrm{g} / \mathrm{mL}), 30$ min prior the addition to the organ bath $(n=4)$. Phenolic compounds significantly inhibited the neuromuscular blockade of Bjssu in the following order of potency: vanillic acid $>$ protocatechuic $=$ vanillin. Vanillic acid added $10 \mathrm{~min}$ after the Bjssu venom was also able to avoid the venomblockade evolution. The mutagenicity assay indicated that all phytochemicals were unable to increase the number of revertants, demonstrating the absence of mutagenic activity. This study

\footnotetext{
"Corresponding author.
} 
demonstrated both the safety and therapeutical potential of the three phenolic compounds as novel complementary anti-bothropic agents.

\author{
Keywords
}

Ames Test, Baru, Bothrops jararacussu Venom, Vanillic Acid, Vanillin

\title{
1. Introduction
}

Natural phenolic compounds have an aromatic ring bearing one or more hydroxyl or etherified substituents, being known due the ability to complex proteins by hydrogen bonding. Among them, compounds such as protocatechuic (1, PCA) and vanillic (2, VA) acids, both universal among the angiosperms [1]; and the aldehyde vanillin (3, VN) have closely related structures (Figure 1), which justify the similarity in their biological activity [2].

Dipteryx alata Vogel (Leguminosae), a native plant from the Brazilian savannah and popularly known as ba$r u$ [3], contains 18 compounds already identified and among them the three phenolic derivatives (PCA, VA, and VN) of biomedical relevance [4].

The biological activity of these compounds has been characterized, and revealed their potential as antioxidants [5], scavengers of active oxygen species and electrophiles [6], blockers of nitration [7], and metal chelators [8]. Despite of their environmental relevance considering the endangered situation of the Brazilian Cerrado biome, a preliminary survey for biological activities justifies the bio-prospection, due to the potential of baru as a source for medicinal use, nutritional food, pharmaceutical, and cosmetic compounds. The controlled bio-prospection could allow the valorization of Cerrado's plants, and their sustainable use, contributing to the environment protection.

One of the medicinal interests on baru compounds is their use as anti-ophidian medicine. Bothrops snakebites, including the Bothrops jararacussu snake, are the most relevant snake accidents in Brazil, not only because the number of accidents, but also by the severity of symptoms, which includes high level of pain, inflammation, hemorrhage and myonecrosis. The attributed clinical signs result from proteases/phospholipases/thrombin-like enzymes and peptides present in the venom [9] [10]. Despite of the systemic antigen-antibody action of the antiserum, the local manifestations of Bothrops envenomation are only partially avoided [11]. Thus, strategies to minimize the effects at the bite local would corroborate to avoid unwanted sequels, such as a limb amputation.

Nanotechnology, an innovation of the pharmaceutical sciences, can contribute to the development of a supplementary medicine in order to improve serum therapy [12]. Nevertheless, before this step is achieved, the safety assessment is a crucial protocol.

In this study, PCA, VA, and VN from Dipteryx alata were assayed in a pre-incubation model of a mouse phrenic nerve-diaphragm (PND) preparation, used to measure the in vitro neuromuscular activity of $B$. jararacussu venom [13]. The mutagenic activity of these compounds were assessed by the Salmonella microsome assay (Ames test), using S. typhimurium test strains TA98, TA97a (to detect frameshift mutations), TA100 (to detect base-pair-substitution mutations) and TA102 (normally used to detect mutagens that cause oxidative damage and base-pair-substitution mutations), in the presence or absence of in vitro metabolizing systems [14][16]. Results of genetic toxicological tests, combined with an adequate pharmacology profile, have been used to<smiles>[R]Oc1cc([R])ccc1O</smiles>

1: $\mathrm{R}^{1}=\mathrm{COOH}, \mathrm{R}^{2}=\mathrm{H}$

2: $\mathrm{R}^{1}=\mathrm{COOH}, \mathrm{R}^{2}=\mathrm{CH}_{3}$

3: $\mathrm{R}^{1}=\mathrm{CHO}, \mathrm{R}^{2}=\mathrm{CH}_{3}$

Figure 1. The structures of tested antibothropic phenolics. 1: protocatechuic acid (PCA), 2: vanillic acid (VA), 3: vanillin (VN). 
approve clinical trials of novel drug candidates [17].

\section{Material and Methods}

\subsection{Plant Material and Extraction}

The barks of an adult Dipteryx alata Vogel tree were collected in Pedro Afonso (Tocantins, Brazil), and identified by Institute of Agronomy of Campinas. The voucher specimen was deposited (IAC 50629) at the herbarium of Institute of Agronomy of Campinas. The D. alata barks $(1.269 \mathrm{~kg})$ were dried at $37^{\circ} \mathrm{C}$ over $48 \mathrm{~h}$ and then powdered, ground in a mill, macerated (200 g, during 5 days) in $2 \mathrm{~L}$ of $70 \%$ ethanol, being the suspension percolated (under protection against light) at $20 \mathrm{drops} / \mathrm{min}$, resulting in a $20 \%(\mathrm{~m} / \mathrm{v})$ hydroalcoholic extract. Then, the extract was concentrated under reduced pressure and lyophilized, providing a residue of $170 \mathrm{~g}$, reaching $85 \%$ of efficiency [18].

\subsection{Isolation}

Part of the above described residue (50 g) was dissolved in a 80:20 MeOH: $\mathrm{H}_{2} \mathrm{O}$ mixture, and partitioned successively with the corresponding solvents to give hexane (1.5 g), dichloromethane $\left(\mathrm{CH}_{2} \mathrm{Cl}_{2}, 18\right.$ g), ethyl acetate (EtOAc, $3.7 \mathrm{~g}$ ) and methanol (MeOH residue, $21 \mathrm{~g}$ ) fractions. The $\mathrm{CH}_{2} \mathrm{Cl}_{2}$ fraction was submitted to a silica-gel flash column chromatography and eluted with hexane-EtOAc (9:1 to EtOAc) to give 12 subfractions. These subfractions were further successively flash-chromatographed in silica gel and purified by Sephadex LH-20 column chromatography, eluted with hexane- $\mathrm{CH}_{2} \mathrm{Cl}_{2}-\mathrm{MeOH}-\mathrm{H}_{2} \mathrm{O}$ (2:2:1) to yield 18 compounds, among them the phenolic derivatives protocatechuic acid (PCA, 1), vanillic acid (VA, 2) and vanillin (VN, 3) [4].

\subsection{Compounds Solubilization}

In order to use the phenolic derivatives in the pharmacological assays (see below), they were previously solubilized as follows: PCA (compound 1) in $30 \mu \mathrm{L}$ of dimethyl sulfoxide (DMSO, Sigma Chemical Co., St. Louis, MO, USA); VA and VN (compounds 2 and 3, respectively) in $15 \mu \mathrm{L}$ of polyethylene glycol (PEG 400). The concentration of the solubilizing agents did not cause changes on basal response of the neuromuscular preparations, according to Cintra-Francischinelli et al. [19].

\subsection{Pharmacological Assays}

\subsubsection{Crude Snake Venom}

Bothrops jararacussu venom (Bjssu) was collected from two adult specimens kept in the "Serpentário do Centro de Estudos da Natureza”-Center for Nature Studies Snake Pit-CEN. The venom was lyophilized and certified by Professor Dr. José Carlos Cogo from University of Vale do Paraiba, Univap, SP, Brazil.

\subsubsection{Animals}

Male Swiss white mice (26 - 32 g) were supplied by Anilab (Animais de Laboratório, Paulínia, SP, Brazil). The animals were housed at $25^{\circ} \mathrm{C} \pm 3^{\circ} \mathrm{C}$ on a $12 \mathrm{~h}$ light/dark cycle and they had access to food and water ad libitum. This study (protocol number A013/CEUA/2011) was approved by the institutional Committee for Ethics in Research of University of Vale do Paraiba, and the experiments were performed following the guidelines of the Brazilian College for Animal Experimentation.

\subsubsection{Mouse Phrenic Nerve-Diaphragm Muscle (PND) Preparation}

The phrenic nerve-diaphragm [20] was obtained from mice previously anesthetized with halothane (Cristália, Brazil) and killed by exsanguination. The diaphragm was removed and mounted under a tension of $5 \mathrm{~g} / \mathrm{cm}$ in a 5 $\mathrm{mL}$ organ bath containing aerated Tyrode solution (control) with the following composition (mM): $\mathrm{NaCl} 137$; $\mathrm{KCl}$ 2.7; $\mathrm{CaCl}_{2}$ 1.8; $\mathrm{MgCl}_{2}$ 0.49; $\mathrm{NaH}_{2} \mathrm{PO}_{4}$ 0.42; $\mathrm{NaHCO}_{3}$ 11.9; and glucose 11.1. After equilibration with 95\% $\mathrm{O}_{2} / 5 \% \mathrm{CO}_{2}(\mathrm{v} / \mathrm{v})$, the $\mathrm{pH}$ of this solution was 7.0 . The PND preparations were indirectly stimulated with supramaximal stimuli (4× threshold, $0.06 \mathrm{~Hz}, 0.2 \mathrm{~ms}$ ) delivered from an electrical stimulator (model ESF-15D, Ribeirão Preto, Brazil) directly to the nerve by bipolar electrodes. Isometric twitch tension was recorded with a force displacement transducer (cat. 7003, Ugo Basile, Italy) coupled to a 2-Channel Recorder Gemini physio- 
graph device (cat. 7070, Ugo Basile) via a Basic Preamplifier (cat. 7080, Ugo Basile). The PND myographic recording was performed according to Ferraz et al. [21]. PND was allowed to stabilize for at least 20 min before the experiments.

\subsubsection{Experimental Protocols}

Control PND preparations $(n=4)$ were submitted to Tyrode nutritive solution in order to maintain them. Other PND preparations were submitted to the following phenolic derivatives concentrations, which were based in previous studies [21]: PCA and VA $(200 \mu \mathrm{g} / \mathrm{mL}, \mathrm{n}=4), \mathrm{VN}(50 \mu \mathrm{g} / \mathrm{mL}, \mathrm{n}=4)$ and B. jararacussu venom 40 $\mu \mathrm{g} / \mathrm{mL}(\mathrm{n}=4)$. New PND preparations were also pre-incubated with the same concentrations of the phenolic derivatives, during 30 min prior to addition into the organ bath. This assay was carried out in order to verify the ability of the phenolic compounds to neutralize the in vitro neurotoxic effect of the Bjssu crude venom $(n=4)$.

\subsection{In Vitro Mutagenicity Assay}

Mutagenic activity was tested by the Salmonella/microsome assay, using the S. typhimurium tester strains TA98, TA100, TA102 and TA97a [22], which were kindly provided by B. N. Ames (Berkeley, CA, USA), with and without metabolization by the preincubation method [15]. The strains from frozen cultures were grown overnight for 12 - 14 h, in Oxoid Nutrient Broth No. 2. The S9 fraction, prepared from livers of Sprague-Dawley rats treated with the polychlorinated biphenyl mixture Aroclor 1254 (500 mg/kg), was purchased from Molecular Toxicology Inc. (Boone, NC, USA) and freshly prepared before each test. The metabolic activation system consisted of $4 \%$ of S9 fraction, $1 \%$ of $0.4 \mathrm{M} \mathrm{MgCl}_{2}, 1 \%$ of $1.65 \mathrm{M} \mathrm{KCl}, 0.5 \%$ of $1 \mathrm{M}$ D-glucose-6-phosphate disodium, $4 \%$ of $0.1 \mathrm{M}$ NADP, $50 \%$ of $0.2 \mathrm{M}$ phosphate buffer, and 39.5\% sterile distilled water [15]. The phenolic compounds of $D$. alata extract were dissolved in DMSO in order to obtain the nontoxic concentrations. The tested concentrations were selected based on a preliminary toxicity test. In all subsequent assays, the upper limit of the dose range tested was either the highest nontoxic dose or the lowest toxic dose determined in this preliminary assay. Toxicity was apparent either as a reduction in the number of histidine revertants (His+), or as an alteration in the auxotrophic background (i.e., background lawn). The concentrations varied from 0.78 to 6.25 $\mathrm{mg} /$ plate for PCA, 0.39 to $3.13 \mathrm{mg} /$ plate for VA and 0.1 to $0.78 \mathrm{mg} /$ plate for VN.

All concentrations of the phenolic compounds to be tested were previously added to $0.5 \mathrm{~mL}$ of $0.2 \mathrm{M}$ sodium phosphate buffer (pH 7.4), or to $0.5 \mathrm{~mL}$ de $4 \%$ S9 mixture, with $0.1 \mathrm{~mL}$ of bacterial culture and then incubated at $37^{\circ} \mathrm{C}$ for $20 \mathrm{~min}$. Next, $2 \mathrm{~mL}$ of top agar $(0.6 \%$ agar, histidine and biotin $0.5 \mathrm{mM}$ each, and $0.5 \% \mathrm{NaCl})$ was added, and the mixture was poured on to a plate containing minimal glucose agar (1.5\% Bacto-Difco agar and 2\% glucose in Vogel-Bonner medium E). The plates were incubated at $37^{\circ} \mathrm{C}$ for $48 \mathrm{~h}$ and the His(+) revertant colonies were counted manually. All experiments were carried out in triplicate. The standard mutagens used as positive controls in experiments without S9 mix were 4-nitro-O-phenylenediamine $(10 \mu \mathrm{g} / \mathrm{plate})$ for TA98 and TA97a, sodium azide $(1.25 \mu \mathrm{g} /$ plate $)$ for TA100 and mitomycin $(0.5 \mu \mathrm{g} / \mathrm{plate})$ for TA102. 2-anthramine (1.25 $\mu \mathrm{g} / \mathrm{plate})$ was used with TA98, TA97a and TA100 and 2-aminofluorene $(1.25 \mu \mathrm{g} / \mathrm{plate})$ with TA102 in the experiments with metabolic activation. DMSO (solvent) was used as a negative control ( $50 \mu \mathrm{L} / \mathrm{plate}$ ).

The mutagenic index (MI) was calculated for each concentration tested, and considered as the average number of revertants per plate obtained by the test compound divided by the average number of revertants per plate in the negative (solvent) control. A sample was considered mutagenic when a dose-response relationship was detected and a two-fold increase in the number of mutants $(\mathrm{MI} \geq 2)$ was observed with at least one concentration [23].

\subsection{Statistical Analysis}

Each experimental protocol from the pharmacological assays was repeated at least four times and the results are shown as mean \pm SEM. The number of experiments (n) is indicated in the legend of each figure. Student's $t$-test was used for statistical comparison of the data and the confidence level was set as $5 \%$ (alpha $=0.05$ ). The results of the mutagenicity tests were analyzed with the Salanal statistical software package (US Environmental Protection Agency, Monitoring Systems Laboratory, Las Vegas, NV, version 1.0, from Research Triangle Institute, RTP, North Carolina, USA), adopting the Bernstein et al. [24] model. The data (revertants/plate) were assessed by analysis of variance (ANOVA), followed by linear regression. 


\section{Results and Discussion}

The deforestation process and associated factors have been studied. Both science and technology have been used to protect human health and environment, and to promote innovative green-business practices [25]. Plants with medicinal properties take important role in the sustainability concept. This concept creates and maintains the condition in which human beings and nature can coexist in a productive harmony, allowing social, economic and other requirements of the present and future generations [26].

The Brazilian biome known as Cerrado has been extensively threatened in the last decades. Many species of plants could disappear even before their medicinal properties could be studied [27]. D. alata is a very appreciated specimen by the Cerrado population due to its great value for wood-industry, to recover deforested areas, and specially as a food source [28]. In addition, its medicinal properties as antiophidian agent was previously recognized [4] [21] [29].

The antiophidian properties of three natural phenolic compounds PCA (1), VA (2), and VN (3) found in D. alata [4], whose structures are shown in Figure 1, is showed here for the first time in the literature.

Vanillic acid is an oxidized form of VN and exhibits more free radical scavenging activity than VN [30]. VA has antioxidant, antimicrobial and anti-mutagenic activities and can exhibit a chemopreventive effect in experimentally induced carcinogenesis in rats [31]-[34].

Moreover, VA can scavenge free radical species, having cardioprotective properties, and it could repress fibrogenesis and inflammation in the chronically injured liver [35]-[37]. VN is used as a flavoring agent in food and cosmetics, having well-studied antimicrobial [38] [39], anti-mutagenic, antioxidant, and anti-carcinogenic activities [39]-[41].

Vanillic acid and PCA are commonly derivatives of hydroxybenzoic acid or benzoic acid. According to Anter et al. [42], PCA did not exhibit any genotoxic effect. However, it has an antigenotoxic property against the hydrogen-peroxide effects, exhibiting tumoricidal activity, and apoptosis-induction in HL-60 leukemic cells.

Figure 2 shows the pharmacological effect of the phenolic compounds. VN exhibited bigger potency (around $4 \times$ ) than VA and PCA, since only $50 \mu \mathrm{g} / \mathrm{mL}$ vanillin was used in comparison to the $200 \mu \mathrm{g} / \mathrm{mL}$ of VA and PCA. VN also exhibited a facilitatory effect measured by increased twitches amplitude, at least during 40 min (p < 0.05 when compared to the control group).

Probably the facilitatory effect of VN was associated to its reactive electrophilic character. The ideal phytochemical substance for further neutralization assays with Bjssu could be VA, since it showed the better profile, having no significant difference with control (Tyrode solution). It is important to observe that VN and PCA

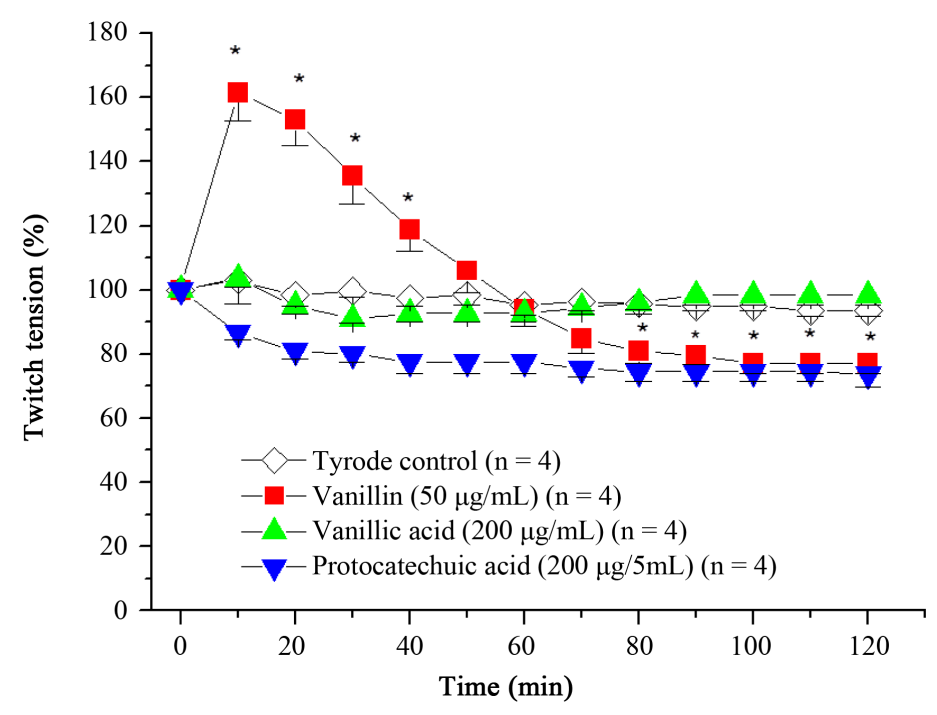

Figure 2. Pharmacological activity evaluation (mouse phrenic nervediaphragm preparation, indirect stimuli). The phenolic compounds profile at the selected concentrations and number of experiments (n) are shown in the figure. Each point represents the mean \pm SEM. ${ }^{*}=p<0.05$ in comparison with the Bjssu venom. 
showed significant differences when compared to the control group from 80 min to $120 \mathrm{~min}$.

Figure 3 shows the in vitro preincubation with each phytochemical prior the addition of Bjssu venom and the effect of the crude Bjssu venom alone. The in vitro irreversible neuromuscular blockade of $B$. jararacussu venom (Bjssu) is well-known [13].

Bothrops jararacussu venom has two basic phospholipase $\mathrm{A}_{2}$ homologues, namely bothropstoxin-I (BthTX-I, a Lys49-PLA2) [43] and bothropstoxin-II (BthTX-II, an Asp49-PLA2) [44] [45]. BthTX-I is considered the main myotoxin from the venom since it is able to reproduce in vitro the neurotoxicity and the myonecrosis of the crude venom [43], being this characteristic the main reason of the interest in the myotoxin. BthTX-I has a presynaptic nature at $0.35 \mu \mathrm{M}$, which is not sufficient to cause muscle fiber depolarization [46]. The Asp49 to Lys49 substitution in the catalytic center (only in the calcium-binding loop) explains the lack of enzymatic action in BthTX-I, due to the loss of ability to bind $\mathrm{Ca}^{2+}[47]$.

Chemically, the mechanism of interaction between the snake venom and the plant includes hydrogen-bonds, electrostatic bonds, Vand der Waals forces, hydrophobic bonds, formation of inactive acid-base complexes protein precipitation and covalent bonds [48]-[52]. The tested phenolic compounds protected the PND preparation against the neurotoxic effect of the venom in the following order: VA $>$ PCA $=$ VN.

Acid-base complexation does not explain PCA activity, since PCA did not show the same ability in neutralizing the venom neuromuscular blockade as VA, and the phenolic groups probably have an important role. The chemical difference between VA and PCA is the methylation of the meta-hydroxyl group. This methylation did facilitate the interaction between the para-hydroxyl groups with venom's constituents, making VA a better venom-inhibitor than PCA. PCA has both hydroxyl groups bonded intramolecularly. Interestingly, VA was isolated from the active fraction 7 of D. alata against Bjssu [29], showing the importance of biomonitoring studies.

Vanillic acid was also evaluated after 10 min of Bjssu venom action (Figure 4), in a post-venom model. Even in this condition, VA was able to counteract the venom myotoxic activity, significantly protecting $\left({ }^{*} \mathrm{p}<0.05\right)$ the tissue against the venom damage.

This post-venom model has been commonly used to observe the plant extract potency, in a better mimic model of the ophidian accident than the preincubation model. Hydroalcoholic extracts of leaves from Casearia gossypiosperma [53] and Vellozia flavicans [54] were validated using the same post-venom model. In all cases, the initial damage induced by the crude Bjssu venom was irreversible, but the damage progression was controlled, conferring an anti-bothropic property to those plants.

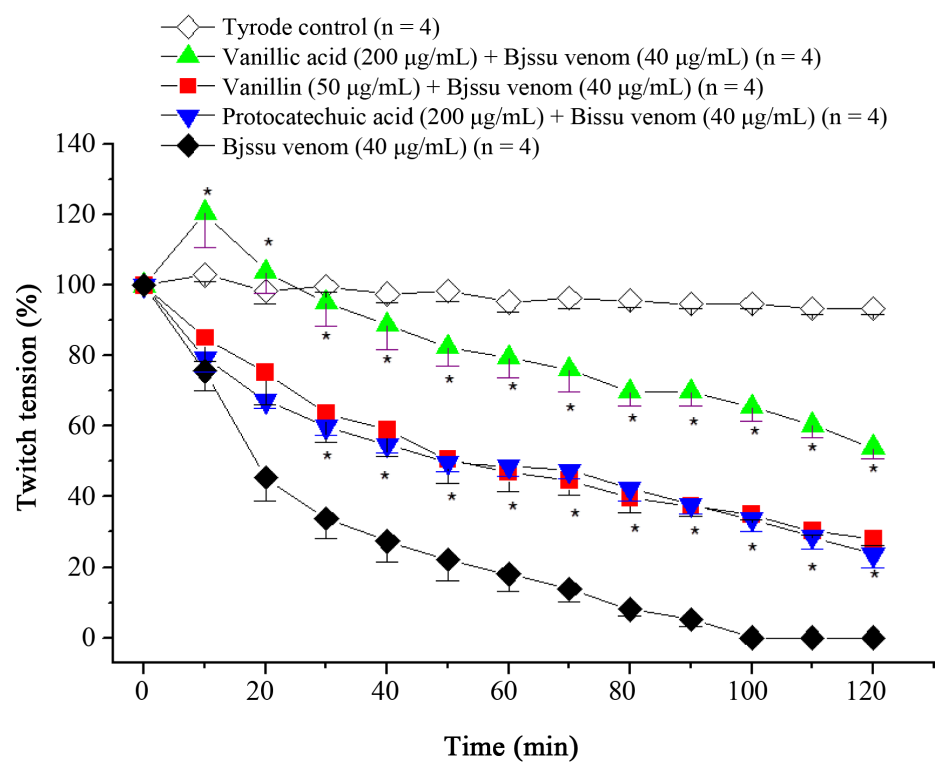

Figure 3. Pharmacological activity evaluation (mouse phrenic nerve-diaphragm preparation, indirect stimuli). Each phenolic compound was preincubated prior Bjssu addition. The concentrations and the number of experiments (n) are shown in the figure. Each point represents the mean \pm SEM. ${ }^{*}=p<0.05$ in comparison with the Bjssu venom. 

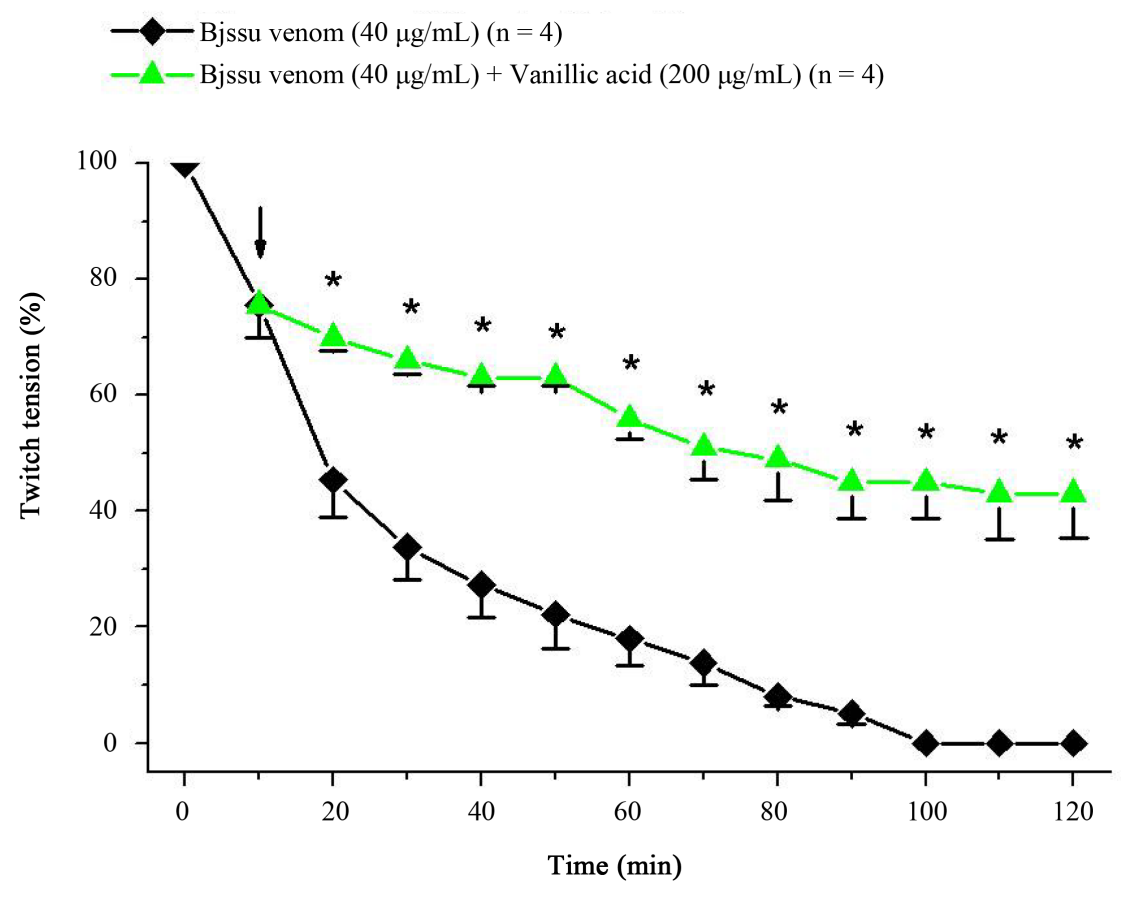

Figure 4. Pharmacological activity evaluation (mouse phrenic nerve-diaphragm preparation, indirect stimuli) of Vanillic acid in a post-venom model. The concentrations and the number of experiments (n) are shown in the figure. Each point represents the mean \pm SEM. ${ }^{*}=\mathrm{p}<0.05$ in comparison with the venom. Arrow: time of Vanillic acid addition.

The balance between the therapeutic and toxicological effects of a compound is a very important measure of its usefulness as a drug. Therefore, the determination of the potential mutagenic effect of any drug under development is mandatory [55]. The Ames assay, which is recommended for testing the mutagenicity of chemical compounds with potential pharmacological application [56] was used in the present study.

In previous studies, Esteves-Pedro et al. [18] showed that the D. alata Vogel extract had no mutagenic effect by Ames test on the strains tested, in either the presence or absence of metabolic activation. To complement the preliminary results [18] and considering the promising results obtained in the present study, the mutagenic activity of the isolated compounds of D. alata Vogel extract was also assessed (Tables 1-3). These Tables list the mean number of revertants/plate (M), the standard deviation (SD) and the mutagenic index (MI) after the treatments with VA, PCA and VN respectively, observed in S. typhimurium strains TA98, TA100, TA102 and TA97a in the presence (+S9) and absence (-S9) of metabolic activation.

The mutagenicity assays show that none of the phenolic compounds induced any increase in the number of revertant colonies compared to the negative control group, indicating the absence of any mutagenic activity. The absence of mutagenicity against $S$. typhimurium bacterial strains in the Ames assay of these compounds is a positive step towards determining its safe use in medicine. Considering the biological properties of these compounds, a lack of mutagenic effect in the bacterial systems tested is highly relevant.

In addition, the genotoxic and anti-genotoxic effects of VA were determinated on mitomycin C-induced DNA damage in human blood lymphocyte cultures in vitro by the cytokinesis-block micronucleus test and the alkaline comet assay. The results showed that VA could prevent oxidative damage to DNA and chromosomes when used at appropriate low doses [57]. VA also induced an inhibitory effect on the mutagenicity of 3-(5-nitro-2-furyl) acrylic acid (5NFAA) and sodium azide [58]. Stagos et al. [59] evaluated the mutagenicity of the PCA; and the results showed no mutagenic effect and no significant effect on bleomycin-induced mutagenicity. According to Shaughnessy et al. [60], VN is a dietary antimutagen that reduces the spontaneous mutant frequency in $S$. typhimurium strain TA104 (hisG428, rfa, uvrB, pKM101) by 50\%, when added to assay plates.

Taken together our results, which are also corroborated with data from literature, these phytochemicals are not mutagenic, and they act as antimutagens according to other studies [39] [41] [42] [57] [59]. These results should stimulate new research in order to provide medicines using these safe molecules and nanotechnology to treat 
Table 1. Mutagenic activity expressed as the mean and standard deviation of the number of revertants/plate and the mutagenic index (in brackets), for the strains TA98, TA100, TA102, and TA97 of S. typhimurium after treatment with phytochemical 4-hydroxy-3-methoxybenzoic (Vanillic acid) isolated from D. alata Vogel, with (+S9) and without (-S9) metabolic activation.

\begin{tabular}{|c|c|c|c|c|c|c|c|c|c|}
\hline \multirow{3}{*}{\multicolumn{2}{|c|}{$\begin{array}{c}\text { Treatments } \\
\text { mg/plate }\end{array}$}} & \multicolumn{8}{|c|}{ Number of revertants $(\mathrm{M} \pm \mathrm{SD}$ )/plate and (MI) } \\
\hline & & \multicolumn{2}{|c|}{ TA 98} & \multicolumn{2}{|c|}{ TA 100} & \multicolumn{2}{|c|}{ TA 102} & \multicolumn{2}{|c|}{ TA 97a } \\
\hline & & $-\mathrm{S} 9$ & +S9 & $-\mathrm{S9}$ & +S9 & $-\mathrm{S} 9$ & +S9 & $-\mathrm{S} 9$ & +S9 \\
\hline \multirow{7}{*}{ 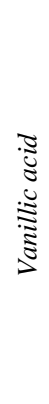 } & $0.0^{\mathrm{a}}$ & $28 \pm 2$ & $24 \pm 2$ & $104 \pm 15$ & $95 \pm 6$ & $271 \pm 18$ & $461 \pm 21$ & $125 \pm 15$ & $96 \pm 10$ \\
\hline & 0.39 & $28 \pm 5(1.0)$ & $21 \pm 3(0.9)$ & $113 \pm 11(1.1)$ & $95 \pm 11(1.0)$ & $241 \pm 25(0.9)$ & $518 \pm 13(1.1)$ & $98 \pm 13(0.8)$ & $98 \pm 5(1.0)$ \\
\hline & 0.78 & $41 \pm 2(1.5)$ & $18 \pm 3(0.8)$ & $115 \pm 15$ & $88 \pm 14(0.9)$ & $237 \pm 13(0.9)$ & $522 \pm 16(1.1)$ & $108 \pm 10(0.9)$ & $108 \pm 2(1.1)$ \\
\hline & 1.56 & $31 \pm 5$ (1.1) & $21 \pm 2(0.9)$ & $91 \pm 7$ (0.9) & $89 \pm 7(0.9)$ & $268 \pm 10(1.0)$ & $500 \pm 20(1.1)$ & $113 \pm 9(0.9)$ & $103 \pm 13(1.1)$ \\
\hline & 2.34 & $27 \pm 2(1.0)$ & $20 \pm 1(0.8)$ & $96 \pm 11(0.9)$ & $84 \pm 7(0.9)$ & $315 \pm 8(1.2)$ & $487 \pm 15(1.1)$ & $96 \pm 3(0.8)$ & $103 \pm 18$ \\
\hline & 3.13 & $27 \pm 5(1.0)$ & $21 \pm 4(0.9)$ & $99 \pm 8(0.9)$ & $92 \pm 12(1.0)$ & $293 \pm 19$ (1.1) & $471 \pm 13(1.0)$ & $84 \pm 6(0.7)$ & $97 \pm 5(1.0)$ \\
\hline & Ctrol+ & $2064 \pm 87^{\mathrm{b}}$ & $1213 \pm 33^{\mathrm{e}}$ & $1252 \pm 124^{\mathrm{c}}$ & $1870 \pm 69^{\mathrm{e}}$ & $1173 \pm 47^{\mathrm{d}}$ & $1822 \pm 102^{\mathrm{f}}$ & $1968 \pm 77^{b}$ & $1850 \pm 67^{\mathrm{e}}$ \\
\hline
\end{tabular}

$\mathrm{M} \pm \mathrm{SD}=$ mean and standard deviation; $\mathrm{MI}=$ mutagenicity index; ${ }^{\mathrm{a}}$ Negative control: dimethylsulfoxide (DMSO-50 $\mu \mathrm{L} /$ plate); $\mathrm{Ctrol}+=$ Positive control- ${ }^{\mathrm{b}} 4$-nitro-o-phenylenediamine (NOPD-10.0 $\mu \mathrm{g} /$ plate-TA98, TA97a); ${ }^{\mathrm{c}}$ sodium azide $(1.25 \mu \mathrm{g} / \mathrm{plate}-\mathrm{TA} 100)$; ${ }^{\mathrm{d}}$ mitomycin $(0.5 \mu \mathrm{g} / \mathrm{plate}-\mathrm{TA} 102)$, in the absence of S9 and ${ }^{\mathrm{e}} 2$-anthramine $\left(1.25 \mu \mathrm{g}\right.$ /plate-TA 97a, TA98, TA100); ${ }^{\mathrm{f}}$-aminofluorene $(10.0 \mu \mathrm{g} / \mathrm{plate}$-TA102), in the presence of S9.

Table 2. Mutagenic activity expressed as the mean and standard deviation of the number of revertants/plate and the mutagenic index (in brackets), for the strains TA98, TA100, TA102, and TA97 of S. typhimurium after treatment with phytochemical 3,4-dihydroxybenzoic acid (Protocatechuic acid) isolated from D. alata Vogel, with (+S9) and without (-S9) metabolic activation.

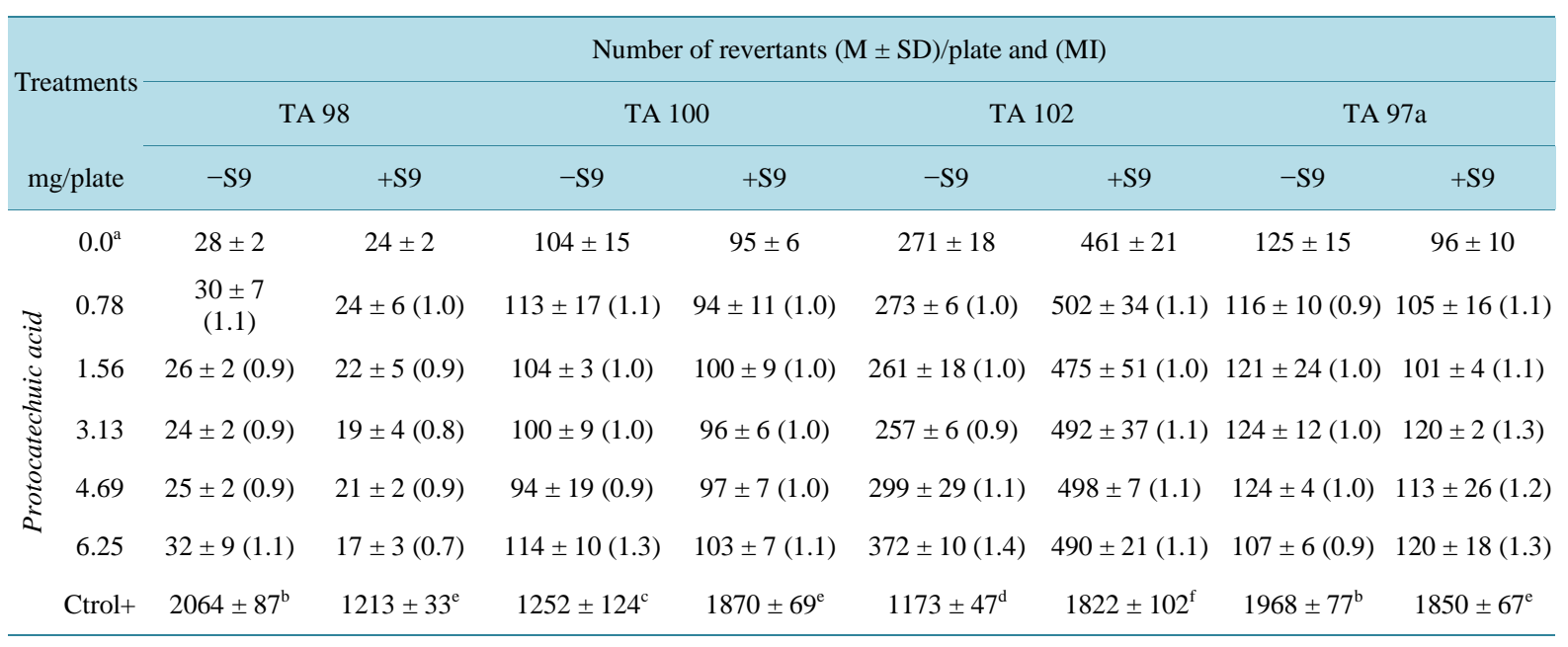

$\mathrm{M} \pm \mathrm{SD}=$ mean and standard deviation; $\mathrm{MI}=$ mutagenicity index; ${ }^{\mathrm{a}}$ Negative control: dimethylsulfoxide (DMSO-50 $\mu \mathrm{L} /$ plate); Ctrol $+=$ Positive control- ${ }^{\mathrm{b}}$ 4-nitro-o-phenylenediamine (NOPD-10.0 $\mu \mathrm{g}$ /plate-TA98, TA97a); ${ }^{\mathrm{c}}$ sodium azide $(1.25 \mu \mathrm{g} / \mathrm{plate}-\mathrm{TA} 100)$; ${ }^{\mathrm{d}}$ mitomycin $(0.5 \mu \mathrm{g} / \mathrm{plate}$-TA102), in the absence of S9 and ${ }^{\mathrm{e}} 2$-anthramine $\left(1.25 \mu \mathrm{g} /\right.$ plate-TA 97a, TA98, TA100); ${ }^{\mathrm{f}}$-aminofluorene $(10.0 \mu \mathrm{g} / \mathrm{plate}$-TA102), in the presence of S9.

several pathological conditions, such as snakebite envenoming.

\section{Conclusion}

Phenolic compounds from $D$. alata significantly protected the neuromuscular preparation against the irreversible neuromuscular blockade-induced by B. jararacussu venom, at different levels: VA > PCA = VN, by unclear mechanisms. VA significantly inhibited the venom-blockade evolution in a post-venom model. Moreover, the results indicated the absence of any mutagenic activity by Ames test; it is important to guarantee its safe use in humans. 
Table 3. Mutagenic activity expressed as the mean and standard deviation of the number of revertants/plate and the mutagenic index (in brackets), for the strains TA98, TA100, TA102, and TA97 of S. typhimurium after treatment with phytochemical 4-hydroxy-3-metoxibenzaldehído (Vanillin) isolated from D. alata Vogel, with (+S9) and without (-S9) metabolic activation.

\begin{tabular}{|c|c|c|c|c|c|c|c|c|c|}
\hline \multirow{3}{*}{\multicolumn{2}{|c|}{$\begin{array}{c}\text { Treatments } \\
\text { mg/plate }\end{array}$}} & \multicolumn{8}{|c|}{ Number of revertants $(\mathrm{M} \pm \mathrm{SD}$ )/plate and (MI) } \\
\hline & & \multicolumn{2}{|c|}{ TA 98} & \multicolumn{2}{|c|}{ TA 100} & \multicolumn{2}{|c|}{ TA 102} & \multicolumn{2}{|c|}{ TA 97a } \\
\hline & & - S9 & +S9 & $-\mathrm{S9}$ & $+\mathrm{S} 9$ & $-\mathrm{S} 9$ & +S9 & $-\mathrm{S9}$ & +S9 \\
\hline \multirow{7}{*}{ 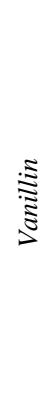 } & $0.0^{\mathrm{a}}$ & $20 \pm 2$ & $30 \pm 2$ & $115 \pm 7$ & $121 \pm 9$ & $313 \pm 24$ & $411 \pm 17$ & $151 \pm 8$ & $143 \pm 8$ \\
\hline & 0.10 & $20 \pm 3(1.0)$ & $33 \pm 3(1.1)$ & $103 \pm 8(0.9)$ & $142 \pm 9(1.2)$ & $375 \pm 15(1.2)$ & $453 \pm 27(1.1)$ & $171 \pm 11(1.1)$ & $192 \pm 6(1.3)$ \\
\hline & 0.20 & $17 \pm 1(0.9)$ & $35 \pm 3(1.2)$ & $111 \pm 11(1.0)$ & $148 \pm 11(1.2)$ & $430 \pm 19(1.4)$ & $496 \pm 13(1.2)$ & $205 \pm 22(1.4)$ & $167 \pm 12(1.2)$ \\
\hline & 0.39 & $19 \pm 3(0.9)$ & $30 \pm 4(1.0)$ & $110 \pm 2(1.0)$ & $143 \pm 10(1.2)$ & $422 \pm 43(1.4)$ & $503 \pm 14(1.2)$ & $186 \pm 12(1.2)$ & $163 \pm 7(1.1)$ \\
\hline & 0.59 & $16 \pm 2(0.8)$ & $37 \pm 3(1.2)$ & $108 \pm 6(0.9)$ & $144 \pm 13(1.2)$ & $367 \pm 26(1.2)$ & $489 \pm 27(1.2)$ & $167 \pm 17(1.1)$ & $167 \pm 5(1.2)$ \\
\hline & 0.78 & $20 \pm 2(1.0)$ & $34 \pm 6(1.1)$ & $108 \pm 10(0.9)$ & $116 \pm 3(1.0)$ & $325 \pm 41(1.0)$ & $445 \pm 21(1.1)$ & $173 \pm 7$ (1.1) & $170 \pm 13(1.2)$ \\
\hline & Ctrol+ & $1319 \pm 41^{\mathrm{b}}$ & $1696 \pm 41^{\mathrm{e}}$ & $1708 \pm 27^{c}$ & $1480 \pm 52^{\mathrm{e}}$ & $1220 \pm 24^{\mathrm{d}}$ & $1825 \pm 55^{f}$ & $1875 \pm 62^{\mathrm{b}}$ & $1623 \pm 48^{\mathrm{e}}$ \\
\hline
\end{tabular}

$\mathrm{M} \pm \mathrm{SD}=$ mean and standard deviation; $\mathrm{MI}=$ mutagenicity index; ${ }^{\mathrm{a}}$ Negative control: dimethylsulfoxide (DMSO-50 $\mu \mathrm{L} /$ plate) Ctrol $+=$ Positive control- ${ }^{\mathrm{b}}$ 4-nitro-o-phenylenediamine (NOPD-10.0 $\mu \mathrm{g}$ /plate-TA98, TA97a); ${ }^{\mathrm{c}}$ sodium azide (1.25 $\mu \mathrm{g} /$ plate-TA100); ${ }^{\mathrm{d}}$ mitomycin $(0.5 \mu \mathrm{g} / \mathrm{plate}$-TA102), in the absence of S9 and ${ }^{\mathrm{e}} 2$-anthramine (1.25 $\mu \mathrm{g}$ /plate-TA 97a, TA98, TA100); ${ }^{\mathrm{f}}$-aminofluorene (10.0 $\mu \mathrm{g} /$ plate-TA102), in the presence of S9.

\section{Acknowledgements}

The authors thank to Roseli B. Torres for the plant identification. This study was supported by FAPESP (04/ 09705-8; 07/53883-6; 08/50669-6; 08/52643-4; 08/11005-5); Capes/Prosup; Probic/Uniso; and USAL:18KAC9/ 463AC01.

\section{References}

[1] Harborne, J.B. (1998) Phytochemical Methods. A Guide to Modern Techniques of Plant Analysys. 3rd Edition, Chapman \& Hall, London.

[2] Lee, S., Monnappa, A.K. and Mitchell, R.J. (2012) Biological Activities of Lignin Hydrolysate-Related Compounds. Biochemistry and Molecular Biology Reports, 45, 265-275.

[3] Lorenzi, H. (1992) Árvores Brasileiras: Manual de Identificação e Cultivo de Plantas Arbóreas Nativas do Brasil. Plantarum, Nova Odessa.

[4] Puebla, P., Oshima-Franco, Y., Franco, L.M., Dos Santos, M.G., Da Silva, R.V., Rubem-Mauro, L. and Feliciano, A.S. (2010) Chemical Constituents of the Bark of Dipteryx alata Vogel, an Active Species against Bothrops jararacussu Venom. Molecules, 15, 8193-8204. http://dx.doi.org/10.3390/molecules15118193

[5] Kaga, V.E. and Tyurinov, Y.Y. (1998) Recycling and Redox Cycling of Phenolic Antioxidants. Annals of the New York Academy of Sciences, 854, 425-434. http://dx.doi.org/10.1111/j.1749-6632.1998.tb09921.x

[6] Zhou, Y.C. and Zheng, R.L. (1991) Phenolic Compounds and an Analog as Superoxide Anion Scavengers and Antioxidants. Biochemical Pharmacology, 42, 1177-1179. http://dx.doi.org/10.1016/0006-2952(91)90251-Y

[7] Kono, Y., Shibata, H., Kodama, Y. and Sawa, Y. (1995) The Suppression of the N-Nitrosating Reaction by Chlorogenic Acid. Biochemical Journal, 312, 947-953.

[8] Brune, M., Rossander, L. and Hallberg, L. (1989) Iron Absorption and Phenolic Compounds: Importance of Different Phenolic Structures. European Journal of Clinical Nutrition, 43, 547-548.

[9] Jorge, M.T., De Campos, F.P., Martins, F.P., Bousso, A., Cardoso, J.L., Ribeiro, L.A., Fan, H.W., França, F.O., Sano-Martins, I.S., Cardoso, D., Ide Fernandez, C., Fernandes, J.C., Aldred, V.L., Sandoval, M.P., Puorto, G., Theakston, R.D. and Warrell, D.A. (1997) Snake Bites by the Jararacuçu (Bothrops jararacussu): Clinicopathological Studies of 29 Proven Cases in São Paulo State, Brazil. Quarterly Journal of Medicine, 90, 323-334. http://dx.doi.org/10.1093/qjmed/90.5.323

[10] Ministério da Saúde (2001) Manual de Diagnóstico e tratamento de acidentes por animais peçonhentos. 2nd Edition, Ministério da Saúde, Brazil.

[11] Warrell, D.A. (1992) The Global Problem of Snaked Bite: Its Prevention and Treatment. In: Gopalakrishnakone, P. and 
Tan, C.K., Eds., Recent Advances in Toxinology Research, National University of Singapore, Singapore, 121-153.

[12] Dwivedi, R. (2014) Silver Nanoparticles Ecofriendly Green Synthesis by Using Two Medicinal Plant Extract. International Journal of Bio-Technology and Research, 3, 61-68.

[13] Rodrigues-Simioni, L., Borgese, N. and Ceccarelli, B. (1983) The Effects of Bothrops jararacussu Venom and Its Components on Frog Nerve-Muscle Preparation. Neuroscience, 10, 475-489. http://dx.doi.org/10.1016/0306-4522(83)90147-1

[14] Ames, B.N., McCann, J. and Yamasaki, E. (1975) Methods for Detecting Carcinogens and Mutagens with the Salmonella/Mammalian-Microsome Mutagenicity Test. Mutation Research, 31, 347-364. http://dx.doi.org/10.1016/0165-1161(75)90046-1

[15] Maron, D.M. and Ames, B.N. (1983) Revised Methods for the Salmonella Mutagenicity Test. Mutation Research/Environmental Mutagenesis and Related Subjects, 113, 173-215. http://dx.doi.org/10.1016/0165-1161(83)90010-9

[16] Gatehouse, D., Haworth, S., Cebula, T., et al. (1994) Recommendations for the Performance of Bacterial Mutation Assays. Mutation Research/Environmental Mutagenesis and Related Subjects, 312, 217-233. http://dx.doi.org/10.1016/0165-1161(94)90037-X

[17] Santos, J.L., Varanda, E.A., Lima, L.M. and Chin, C.M. (2010) Mutagenicity of New Lead Compounds to Treat Sickle Cell Disease Symptoms in a Salmonella/Microsome Assay. International Journal of Molecular Sciences, 11, 779-788. http://dx.doi.org/10.3390/ijms11020779

[18] Esteves-Pedro, N.M., Borim, T., Nazato, V.S., Silva, M.G., Gerenutti, M., Oshima-Franco, Y., Lopes, P.S., dos Santos, M.G., Dal Belo, C.A., Primila Cardoso, C.R., Varanda, E.A. and Groppo, F.C. (2012) In Vitro and in Vivo Safety Evaluation of Dipteryx alata Vogel Extract. BioMed Central Complementary and Alternative Medicine, 12, 9. http://dx.doi.org/10.1186/1472-6882-12-9

[19] Cintra-Francischinelli, M., Silva, M.G., Andreo-Filho, N., Cintra, A.C.O., Leite, G.B., da Cruz Höfling, M.A., Rodrigues-Simioni, L. and Oshima-Franco, Y. (2008) Effects of Commonly Used Solubilizing Agents on a Model NerveMuscle Synapse. Latin American Journal of Pharmacy, 27, 721-726.

[20] Bülbring, E. (1946) Observation on the Isolated Phrenic Nerve Diaphragm Preparation of the Rat. British Journal of Pharmacology, 1, 38-61.

[21] Ferraz, M.C., Parrilha, L.A.C., Moraes, M.S.D., Amaral Filho, J., Cogo, C.J., dos Santos, M.G., Franco, L.M., Groppo, F.C., Puebla, P., Feliciano, A.S. and Oshima-Franco, Y. (2012) The Effect of Lupane Triterpenoids (Dipteryx alata Vogel) in the in Vitro Neuromuscular Blockade and Myotoxicity of Two Snake Venoms. Current Organic Chemistry, 16, 2717-2723. http://dx.doi.org/10.2174/138527212804004481

[22] OECD (1997) OECD Guideline for Testing of Chemicals, Bacterial Reverse Mutation Test.

[23] Varella, S.D., Pozetti, G.L., Vilegas, W. and Varanda, E.A. (2004) Mutagenic Activity of Sweepings and Pigments from a Household-Wax Factory Assayed with Salmonella typhimurium. Food and Chemical Toxicology, 42, 20292035. http://dx.doi.org/10.1016/j.fct.2004.07.019

[24] Bernstein, L., Kaldor, J., McCann, J. and Pike, M.C. (1982) An Empirical Approach to the Statistical Analysis of Mutagenesis Data from the Salmonella Test. Mutation Research/Environmental Mutagenesis and Related Subjects, 97, 267-281. http://dx.doi.org/10.1016/0165-1161(82)90026-7

[25] El-Abbas, M.M., Csaplovics, E. and Deafalla, T.H. (2013) Remote Sensing and Spatial Analysis Based Study for Detecting Deforestation and the Associated Drivers. Proceedings of SPIE 8893, Earth Resources and Environmental Remote Sensing/GIS Applications IV, 88930O, Dresden, 24 October 2013.

[26] US Environmental Protection Agency (EPA). http://www.epa.gov/sustainability/basicinfo.htm

[27] Santos, M.G., Lolis, S.F. and Dal Belo, C.A. (2006) Levantamentos etnobotânicos realizados em duas comunidades de remanescentes de negros da região do Jalapão, Estado do Tocantins. In: Pires, A.L., Cardoso, S. and Oliveira, R., Eds., Sociabilidade Negras. Comunidades Remanescentes, Escravidão e Cultura, Daliana, Belo Horizonte, 29-49.

[28] Togashi, M. and Sgarbieri, V.C. (1995) Avaliação nutricional da proteína e do óleo de semente de baru (Dipteryx alata Vog.). Ciência e Tecnologia de Alimentos, 15, 66-69.

[29] Nazato, V.S., Rubem-Mauro, L., Vieira, N.A.G., Rocha, D.S., Silva, M.G., Lopes, P.S., Dal-Belo, C.A., Cogo, J.C., Dos Santos, M.G., Da Cruz-Höfling, M.A. and Oshima-Franco, Y. (2010) In Vitro Antiophidian Properties of Dipteryx alata Vogel Bark Extracts. Molecules, 15, 5956-5970. http://dx.doi.org/10.3390/molecules15095956

[30] Sasaki, Y.F., Ohta, T., Imanishi, H., Watanabe, M., Matsumoto, K., Tomoko Kato, T. and Shirasu, Y. (1990) Suppressing Effects of Vanillin, Cinnamaldehyde, and Anisaldehyde on Chromosome Aberrations Induced by X-Rats in Mice. Mutation Research Letters, 243, 299-302. http://dx.doi.org/10.1016/0165-7992(90)90146-B

[31] Tsuda, H., Uehara, N., Iwahori, Y., Asamoto, M., Ligo, M., Nagao, M., Matsumoto, K., Ito, M. and Hirono, I. (1994) Chemopreventive Effects of $\beta$-Carotene, $\alpha$-Tocopherol and Five Naturally Occurring Antioxidants on Initiation of He- 
patocarcinogenesis by 2-Amino-3-methylimidazo[4,5-f] Qumoline in the Rat. Japanese Journal of Cancer Research, 85, 1214-1219. http://dx.doi.org/10.1111/j.1349-7006.1994.tb02932.x

[32] Raja, B. and Mol, S.D. (2010) The Protective Role of Vanillic Acid against Acetaminophen Induced Hepatotoxicity in Rats. Journal of Pharmacy Research, 3, 1480-1484.

[33] Tai, A., Sawano, T., Yazama, F. and Ito, H. (2011) Evaluation of Antioxidant Activity of Vanillin by Using Multiple Antioxidant Assays. Biochimica et Biophysica Acta, 1810, 170-177. http://dx.doi.org/10.1016/j.bbagen.2010.11.004

[34] Tai, A., Sawano, T. and Ito, H. (2012) Antioxidative Properties of Vanillic Acid Esters in Multiple Antioxidant Assays. Bioscience, Biotechnology, and Biochemistry, 76, 314-318. http://dx.doi.org/10.1271/bbb.110700

[35] Prince, P.S.M., Dhanasekar, K. and Rajakumar, S. (2011) Preventive Effects of Vanillic Acid on Lipids, Bax, Bcl-2 and Myocardial Infarct Size on Isoproterenol-Induced Myocardial Infracted Rats: A Biochemical and in vitro Study. Cardiovascular Toxicology, 11, 58-66. http://dx.doi.org/10.1007/s12012-010-9098-3

[36] Itoh, A., Isoda, K. and Kondoh, M., Masaya, K., Kiyohito, Y., Masakazu, K. and Makoto, T. (2009) Hepatoprotective Effect of Syringic Acid and Vanillic Acid on Concanavalin A-Induced Liver Injury. Biological and Pharmaceutical Bulletin, 32, 1215-1219. http://dx.doi.org/10.1248/bpb.32.1215

[37] Itoh, A., Isoda, K., Kondoh, M., Masaya, K., Akihiro, W., Kiyohito, Y., Masakazu, K. and Makoto, T. (2010) Hepatoprotective Effect of Syringic and Vanillic Acid on $\mathrm{CCl}_{4}$-Induced Liver Injury. Biological and Pharmaceutical Bulletin, 33, 983-987. http://dx.doi.org/10.1248/bpb.33.983

[38] Santosh Kumar, S., Priyadarsini, K.I. and Sainis, K.B. (2002) Free Radical Scavenging Activity of Vanillin and o-Vanillin Using 1,1-diphenyl-2-picrylhydrazyl (DPPH) Radical. Redox Report, 7, 35-40. http://dx.doi.org/10.1179/135100002125000163

[39] Lirdprapamongkol, K., Kramb, J.P., Suthiphongchai, T., Surarit, R., Srisomsap, C., Dannhardt, G. and Svasti, J. (2009) Vanillin Suppresses Metastatic Potential of Human Cancer Cells through PI3K Inhibition and Decreases Angiogenesis in Vivo. Journal of Agricultural and Food Chemistry, 58, 3055-3063. http://dx.doi.org/10.1021/jf803366f

[40] Liang, J-A., Wu, S-L., Lo, H-Y., Hsiang, C-Y. and Ho, T-Y. (2009) Vanillin Inhibits Matrix Metalloproteinase-9 Expression through Down-Regulation of Nuclear Factor- $\mathrm{\kappa B}$ Signaling Pathway in Human Hepatocellular Carcinoma Cells. Molecular Pharmacology, 75, 151-157. http://dx.doi.org/10.1124/mol.108.049502

[41] Tabassum, S., Amir, S., Arjmand, F., Pettinari, C., Marchetti, F., Masciocchi, N., Lupidi, G. and Pettinari, R. (2013) Mixed-Ligand Cu(II)-Vanillin Schiff Base Complexes; Effect of Coligands on Their DNA Binding, DNA Cleavage, SOD Mimetic and Anticancer Activity. European Journal of Medicinal Chemistry, 60, 216-232. http://dx.doi.org/10.1016/j.ejmech.2012.08.019

[42] Anter, J., Romero-Jiménez, M., Fernández-Bedmar, Z., Villatoro-Pulido, M., Analla, M., Alonso-Moraga, A. and Muñoz-Serrano, A. (2011) Antigenotoxicity, Cytotoxicity, and Apoptosis Induction by Apigenin, Bisabolol, and Protocatechuic Acid. Journal of Medicinal Food, 14, 276-283. http://dx.doi.org/10.1089/jmf.2010.0139

[43] Heluany, N.F., Homsi-Brandeburgo, M.I., Giglio, J.R., Prado-Franceschi, J. and Rodrigues-Simioni, L. (1992) Effects Induced by Bothropstoxin, a Component from Bothrops jararacussu Snake Venom, on Mouse and Chick Muscle Preparations. Toxicon, 30, 1203-1210. http://dx.doi.org/10.1016/0041-0101(92)90436-9

[44] Gutiérrez, J.M., Núñez, J., Díaz, C., Cintra, A.C., Homsi-Brandeburgo, M.I. and Giglio, J.R. (1991) Skeletal Muscle Degeneration and Regeneration after Injection of Bothropstoxin-II, a Phospholipase $\mathrm{A}_{2}$ Isolated from the Venom of the Snake Bothrops jararacussu. Experimental Molecular Pathology, 55, 217-229. http://dx.doi.org/10.1016/0014-4800(91)90002-F

[45] Pereira, M.F., Novello, J.C., Cintra, A.C., Giglio, J.R., Landucci, E.T., Oliveira, B. and Marangoni, S. (1998) The Amino Acid Sequence of Bothropstoxin-II, an Asp-49 Myotoxin from Bothrops jararacussu (Jararacucu) Venom with Low Phospholipase $\mathrm{A}_{2}$ Activity. Journal of Protein Chemistry, 17, 381-386. http://dx.doi.org/10.1023/A:1022563401413

[46] Oshima-Franco, Y., Leite, G.B., Belo, C.A., Hyslop, S., Prado-Franceschi, J., Cintra, A.C., Giglio, J.R., da Cruz-Höfling, M.A. and Rodrigues-Simioni, L. (2004) The Presynaptic Activity of Bothropstoxin-I, a Myotoxin from Bothrops jararacussu Snake Venom. Basic \& Clinical Pharmacology \& Toxicology, 95, 175-182. http://dx.doi.org/10.1111/j.1742-7843.2004.pto 950405.x

[47] Angulo, Y., Olamendi-Portugal, T., Alape-Girón, A., Hyslop, S., Prado-Franceschi, J., Cintra, A.C., Giglio, J.R., da Cruz-Höfling, M.A. and Rodrigues-Simioni, L. (2002) Structural Characterization and Phylogenetic Relationships of Myotoxin II from Atropoides (Bothrops) nummifer Snake Venom, a Lys49 Phospholipase $\mathrm{A}_{2}$ Homologue. The International Journal of Biochemistry \& Cell Biology, 34, 1268-1278. http://dx.doi.org/10.1016/S1357-2725(02)00060-2

[48] de Oliveira, M., Cavalcante, W.L., Arruda, E.Z., Melo, P.A., Dal-Pai Silva, M. and Gallacci, M. (2003) Antagonism of Myotoxic and Paralyzing Activities of Bothropstoxin-I by Suramin. Toxicon, 42, 373-379.

http://dx.doi.org/10.1016/S0041-0101(03)00166-1 
[49] Melo, R.F., Farrapo, N.M., Rocha Jr., D.S., Silva, M.G., Cogo, J.C., Dal Belo, C.A., Rodrigues Simioni, L., Groppo, F.C. and Oshima-Franco, Y. (2009) Antiophidian Mechanisms of Medicinal Plants. In: Keller, R.B., Ed., Flavonoids: Biosynthesis, Biological Effects and Dietary Sources, Nova Science Publishers, New York, 249-262.

[50] Cotrim, C.A., de Oliveira, S.C., Diz Filho, E.B., Fonseca, F.V., Baldissera Jr., L., Antunes, E., Ximenes, R.M., Monteiro, H.S., Rabello, M.M., Hernandes, M.Z., de Oliveira Toyama, D. and Toyama, M.H. (2011) Quercetin as an Inhibitor of Snake Venom Secretory Phospholipase A2. Chemico-Biological Interactions, 189, 9-16. http://dx.doi.org/10.1016/j.cbi.2010.10.016

[51] Dos Santos, J.I., Cardoso, F.F., Soares, A.M., Dal Pai Silva, M., Gallacci, M. and Fontes, M.R. (2011) Structural and Functional Studies of a Bothropic Myotoxin Complexed to Rosmarinic Acid: New Insights into Lys49-PLA 2 Inhibition. Public Library of Science One, 6, e28521.

[52] Li, C.M., Zhang, Y., Yang, J., Zou, B., Dong, X.Q. and Hagerman, A.E. (2013) The Interaction of a Polymeric Persimmon Proanthocyanidin Fraction with Chinese Cobra PLA 2 and BSA. Toxicon, 67, 71-79. http://dx.doi.org/10.1016/j.toxicon.2013.03.005

[53] Camargo, T.M., Nazato, V.S., Silva, M.G., Cogo, J.C., Groppo, F.C. and Oshima-Franco, Y. (2010) Bohrops jararacussu Venom-Induced Neuromuscular Blockade Inhibited by Casearia gossypiosperma Briquet Hydroalcoholic Extract. The Journal of Venomous Animals and Toxins Including Tropical Diseases, 16, 432-441. http://dx.doi.org/10.1590/S1678-91992010000300009

[54] Tribuiani, N., da Silva, A.M., Ferraz, M.C., Silva, M.G., Bentes, A.P., Graziano, T.S., dos Santos, M.G., Cogo, J.C., Varanda, E.A., Groppo, F.C., Cogo, K. and Oshima-Franco, Y. (2014) Vellozia flavicans Mart. ex Schult. Hydroalcoholic Extract Inhibits the Neuromuscular Blockade Induced by Bothrops jararacussu Venom. BMC Complementary Alternative Medicine, 14, 48. http://dx.doi.org/10.1186/1472-6882-14-48

[55] Resende, F.A., Barbosa, L.C., Tavares, D.C., de Camargo, M.S., de Souza Rezende, K.C., e Silva M.L. and Varanda, E.A. (2012) Mutagenicity and Antimutagenicity of (-)-Hinokinin a Trypanosomicidal Compound Measured by Salmonella Microsome and Comet Assays. BioMed Central Complementary and Alternative Medicine, 12, 203. http://dx.doi.org/10.1186/1472-6882-12-203

[56] Müller, R., Kikuchi, Y., Probst, G., Schechtman, L., Shimada, H., Sofuni, T. and Tweats, D. (1999) ICH-Harmonised Guidance on Genotoxicity Testing of Pharmaceuticals: Evolution. Mutation Research/Reviews in Mutation Research, 436, 195-225. http://dx.doi.org/10.1016/S1383-5742(99)00004-6

[57] Erdem, M.G., Cinkilic, N., Vatan, O., Yilmaz, D., Bagdas, D. and Bilaloglu, R. (2012) Genotoxic and Anti-Genotoxic Effects of Vanillic Acid against Mitomycin C-Induced Genomic Damage in Human Lymphocytes in Vitro. Asian Pacific Journal of Cancer Prevention, 13, 4993-4998. http://dx.doi.org/10.7314/APJCP.2012.13.10.4993

[58] Birosová, L., Mikulásová, M. and Vaverková, S. (2005) Antimutagenic Effect of Phenolic Acids. Biomedical Papers, 149, 489-491.

[59] Stagos, D., Kouris, S. and Kouretas, D. (2004) Plant Phenolics Protect from Bleomycin-Induced Oxidative Stress and Mutagenicity in Salmonella typhimurium TA102. Anticancer Research, 24, 743-745.

[60] Shaughnessy, D.T., Setzer, R.W. and DeMarini, D.M. (2001) The Antimutagenic Effect of Vanillin and Cinnamaldehyde on Spontaneous Mutation in Salmonella TA104 Is Due to a Reduction in Mutations at GC but Not AT Sites. Mutation Research, 480-481, 55-69. http://dx.doi.org/10.1016/S0027-5107(01)00169-5 
Scientific Research Publishing (SCIRP) is one of the largest Open Access journal publishers. It is currently publishing more than 200 open access, online, peer-reviewed journals covering a wide range of academic disciplines. SCIRP serves the worldwide academic communities and contributes to the progress and application of science with its publication.

Other selected journals from SCIRP are listed as below. Submit your manuscript to us via either submit@scirp.org or Online Submission Portal.
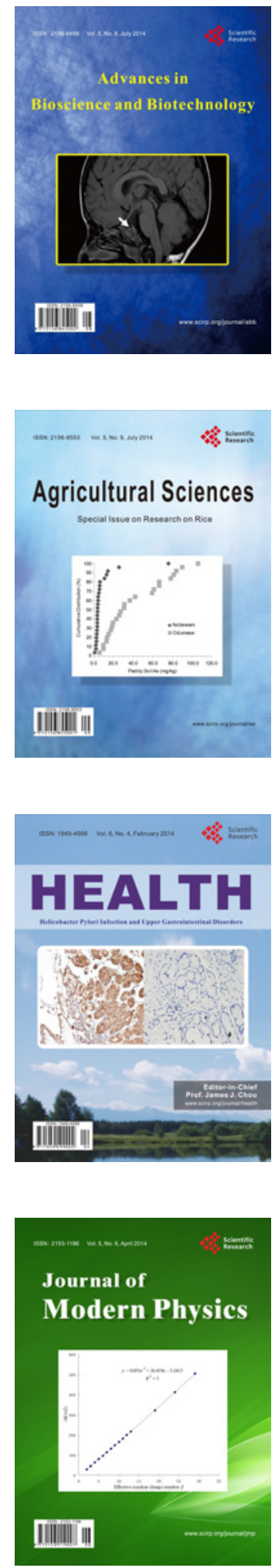
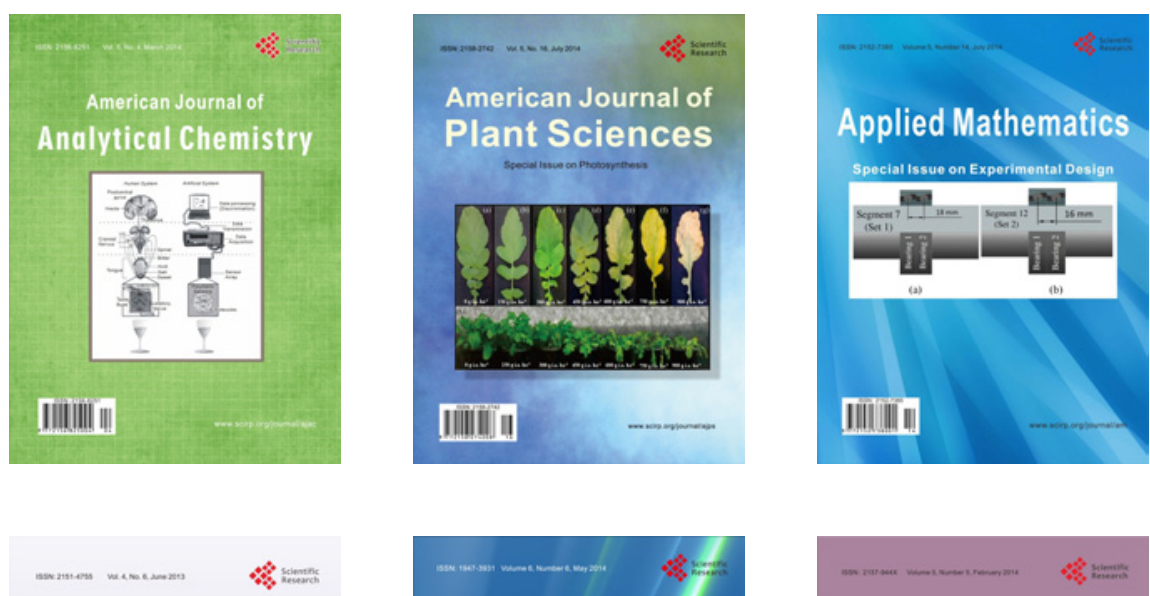

Creative Education
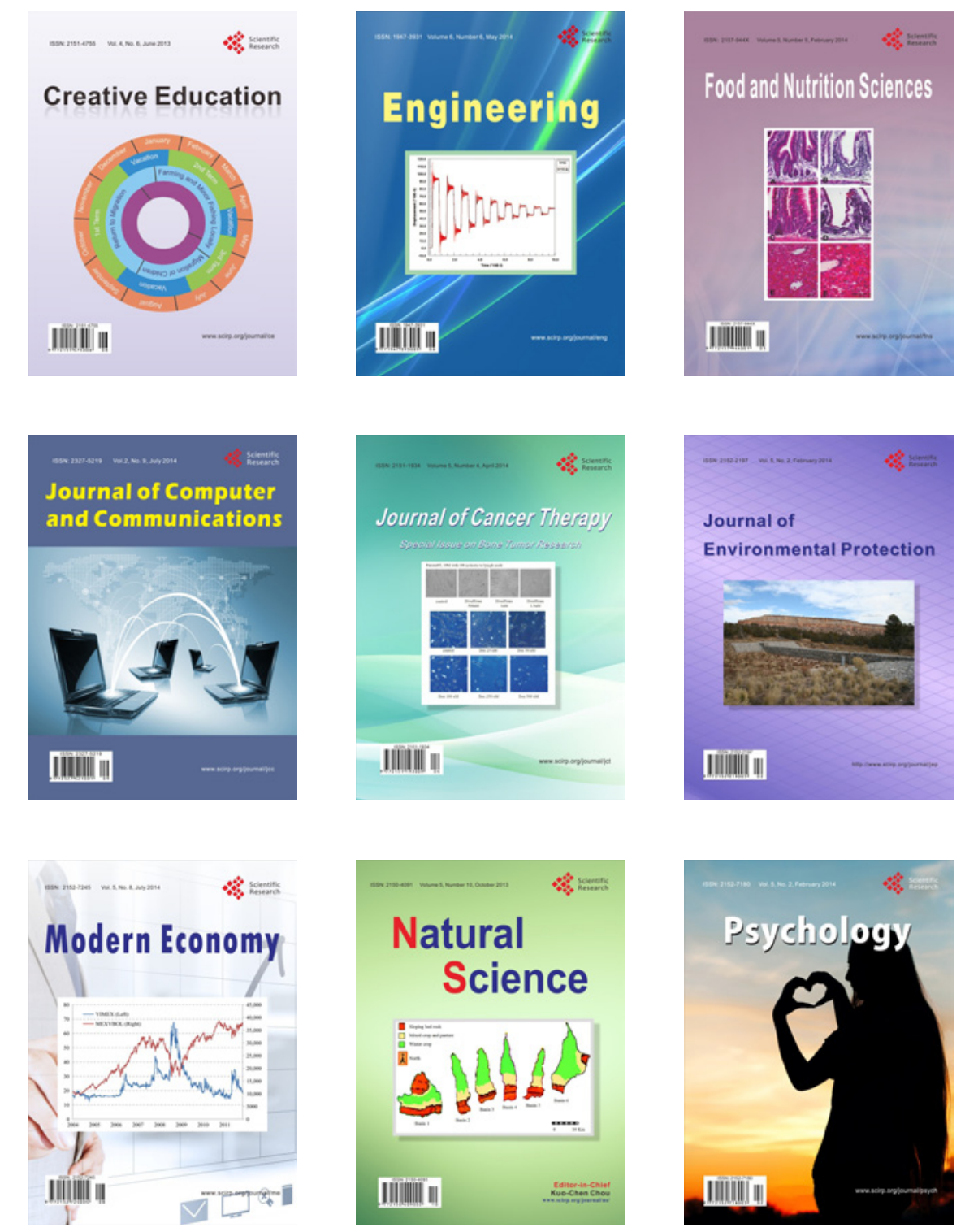